\title{
DÜBLIN
}

Technological University Dublin

ARROW@TU Dublin

\section{Implementing Building Information Modeling in Public Works Projects in Ireland}

\author{
Barry McAuley \\ Technological University Dublin, barry.mcauley@tudublin.ie \\ Alan V. Hore \\ Technological University of Dublin, alan.hore@tudublin.ie \\ Roger West \\ Trinity College, rwest@tcd.ie
}

Follow this and additional works at: https://arrow.tudublin.ie/beschreccon

Part of the Architectural Engineering Commons, Civil Engineering Commons, Construction

Engineering Commons, Construction Engineering and Management Commons, Construction Law

Commons, and the Environmental Design Commons

\section{Recommended Citation}

McAuley, B., Hore, A.V and West, R. (2012) Implementing of Building Information Modelling in Public Works Projects, Proceedings of the 9th European Conference on Product and Process Modelling, Reykjavik, July 25 - 27th 2012. doi:10.1201/b12516-94

This Conference Paper is brought to you for free and open access by the School of Surveying and Construction Management at ARROW@TU Dublin. It has been accepted for inclusion in Conference papers by an authorized administrator of ARROW@TU Dublin. For more information, please contact arrow.admin@tudublin.ie, aisling.coyne@tudublin.ie, gerard.connolly@tudublin.ie.

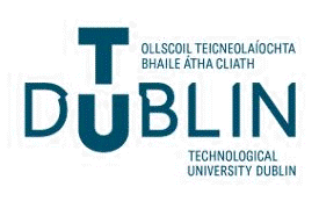




\title{
Implementing Building Information Modeling in Public Works Projects in Ireland
}

\author{
Barry McAuley and Dr. Alan Hore \\ School of Real Estate and Economics, Dublin Institute of Technology, Bolton Street, Dublin 1, Ireland \\ Dr. Roger West \\ Department of Civil Structural and Environmental Engineering, Trinity College Dublin, College Green,
}

Dublin 2, Ireland

\begin{abstract}
The Irish State in recent years has suffered huge financial losses in the public works sector, which has now pushed the Irish Government to explore new ways of controlling cost. This background lead to the introduction of the Capital Works Management Framework in 2007 which aimed to support the certainty of outcome in terms of cost and quality, as well as improved risk management, through the implementation of fixed price contracts. In order to successfully compete within this framework it is recommended by the authors, that Irish Government moves towards the legal mandating of BIM. This can ensure a greater cost certainty for the Irish Government on recent investments that include a $€ 1.5$ billion programme to provide new schools across the country. In an attempt to promote BIM within Ireland a recent pilot workshop and a further ten BIM workshops where commissioned, in which served as the main primary research tool for this paper. Despite the success of these workshops, Ireland is still a long way from embracing BIM and would require the commissioning of a pilot project, from a sceptical Irish Government, to see its true value.
\end{abstract}

\section{INTRODUCTION}

The Irish State in recent years has suffered huge financial losses in the public works sector, which has now pushed the Irish Government to explore new ways of controlling cost. Traditional public forms of contract used, gave rise to major differences between tender and scheme completion prices. In some cases there was an average of $40 \%$ difference between these two figures (Tobin, 2004). In recent years the Irish Government has witnessed a number of high-profile public works jobs that were significantly over budget. This included the Dublin Port Tunnel and the light rail Luas line both of which ended up extensively over budget. This background lead to the introduction of the Capital Works Management Framework (CWMF) in 2007. The CWMF is a series of documents which collectively describe the operating environment, procedures and processes to be followed for the delivery of capital works projects. It incorporates contractual provisions, guidance material and technical procedures covering the public works project lifecycle from inception to final project delivery and review. The aim of the CWMF is to ensure that there is an integrated methodology and a consistent approach to the planning, management and delivery of public capital works projects, with the objectives of greater cost certainty, better value for money and more efficient project delivery. Within the CWMF the Irish government pub- lished a new suite of public sector contracts. The new forms sought to reflect the latest thinking in project and risk management, and, recognise the development of new procurement methods, such as, design and build. These new forms also aimed to support the certainty of outcome in terms of cost, quality and programme.

These new Government Construction Contracts Committee (GCCC) forms of contract where met with huge opposition from near all areas of the Irish Architectural, Engineering and Consultant (AEC) sector. Ireland is essentially a country in a unique period of infrastructure catch-up and it is critical that the contracting relationship is right (Fogarty, 2007). The point is further expanded on by Fogarty who states that under the new contracts, the level of competition will be severely curtailed and small to medium contracting companies, which make up the bulk of the Irish industry, will no longer compete for Government contracts, or even smaller local projects. This view is reinforced by Edge (2006) who further comments that the Government and the public will be the losers with fixed price contracts, all because absolute cost certainty above everything else has become the Government's focus and value for money has been relegated to a secondary status. Despite the outlined concerns from various professionals, the Government introduced these new contracts as the standard method of procurement within public works projects. 
In order for the Irish Government to successfully guarantee a more reliable method of cost certainty and greater value, it is recommended by the authors, that the Irish Government move towards the mandatory use of Building Information Modeling (BIM) on public works projects by following a similar methodology to that adopted in the UK. There is a plan for a phased five-year development within the UK that public works projects will be required to use BIM techniques from 2016. This plan was devised around a hypothesis which defined a scenario in which the Government client would have an estate that was smarter and better equipped to face a low carbon economy, with associated reductions in delivery and carbon emissions.

This paper will set about investigation how BIM can address the following specific goals of the CWMF, namely:

- Move towards greater cost certainty at contract award stage and ensure, as far as practicable, that the accepted tender prices and the final cost are the same.

- Award contracts on the basis of a lump-sum fixed-price to the greatest extent possible.

- Rebalance risk, so that there is optimal allocation of risk.

- Achieve value for money.

- Achieve more efficient delivery of the projects.

\section{METHODOLOGY}

In an attempt to promote BIM within the Irish AEC / FM sector, a recent pilot project was launched by the Royal Institute of Architects in Ireland (RIAI) and the Construction Information Technology Alliance (CITA).This project involved a full professional team working in conjunction with the Department of Education and Science (DOES) on a generic primary school project. The main goals of the workshop where to:

- raise awareness and promote a higher level of understanding of BIM;

- demonstrate a more effective way for teams to collaborate;

- assess / demonstrate some of the BIM software tools available and;

- validate designs through digital analysis;.

This workshop was followed by the recent commissioning of a suite of BIM workshops in 2012. These workshops are to be primarily hosted by CITA and are sponsored by leading professional institutes in Ireland and BIM vendors. The first workshop addressed examining setting an aligned policy for BIM within Ireland and involved a series of round table discussions, addressing areas of concern in regards to the implementing of BIM on public works projects.

These two workshops served as the main primary research tool for this paper and provided data in regards to testing the implementation of BIM on public works projects, as a method for adding cost certainty to contracts. These two different forms of research methodologies will be then triangulated, as this will further increase confidence in research data, creating innovative ways of understanding a phenomenon, challenging or integrating theories, and providing a clearer understanding of the problem (Jick, 1979). This paper will also review the use of BIM initiatives to procure public sector buildings internationally and relate how those experiences can be applied to Ireland.

\section{BIM ON PUBLIC PROJECTS}

The authors conducted a literature review of journal papers, professional publications and research articles in regards to the application of BIM within public works projects. The literature review focused on the three main areas detailed below in order to establish the benefits of using BIM on public works projects in Ireland:

- Irish Public Sector and the Governments roles in implementing BIM.

- Global BIM.

- Barriers to BIM adoption.

\subsection{Irish Public Sector and the Governments role in implementing BIM}

The Irish construction industry has been struck hard since the recession, with the DKM Economic Consultants (2009) reporting that output volumes of around $€ 10.5$ billion are expected by the end of 2011 compared to $€ 38.4$ billion in 2007 . Ireland remains one of the more depressed operating environments for the construction sector and the potential for defaults remain relatively high compared to average default rates over the last 10 years (Henstridge, 2011). The Irish Government has announced a number of large capital expenditure investments to be initiated over the next few years. These investments include the awarding of State contracts worth up to $€ 16$ billion a year for environmentally-friendly policies in 2010 , and, a $€ 1.5$ billion programme in 2012 to provide new schools and extend existing schools across the country.

These public works projects have become a lifeline to struggling contractors in the Irish AEC sector. In order to compete within the public works sector potential firms must operate within the 
Governments recent suite of GCCC forms of contracts. Fogarty (2009) outlined some of his concerns for contractors operating within these contracts, which include the transfer of risk from the employer to the contractor and restrictions that exist for a contractor's ability to claim for amounts over the initial contract sum. Poor project management on the employer's side will also impact the contractor, as well as virtually eliminating claims for increase in labor and material prices. The majority of construction contracts used in Ireland provide for conciliation and arbitration as an alternative means of dispute resolution (Mason Hayes and Curren, 2012).The GCCC suite of contacts are not set up to promote collaboration and effectively through the transfer of risk create a hostile environment. Following the collapse of the 'Celtic Tiger' and, in its wake, the propping-up of the Irish financial system, some views have expressed a new, fairer, more equitable and collaborative way forward can be found in the Irish construction industry to deliver public sector projects (Wren, 2011).

This collaborative approach can be achieved through the re-drafting of the GCCC suite of contracts to include use of BIM technologies. The role of the Irish Government will be critical if the implementation of BIM is to become a reality. In order for the Government to restructure the CWMF to regulate BIM, a number of steps must be undertaken as suggested by Wong et al. (2010). These include

- Policy and programme. The government needs to establish the specific policy of adopting BIM.

- Open standard development. The BIM policy should encourage open standard software development.

- Design information evaluation. The BIM policy should recommend that the design information be explicit and made available to partners, so that the design intent can be easily understood and evaluated.

- BIM implementation department. There is a designated government department or institutions to take up the major responsibilities for BIM implementation initially.

- Adoption by other departments. All departments which can benefit from BIM, should be encouraged to adopt BIM.

- Presentation, promotion and liaison. The government's BIM programme, once established, should be promoted through domestic and global professional bodies for information exchange and continuous improvements.

The Irish Government must play a major driver in this process and review current BIM initiatives and barriers within internationally public sector procurement.

\subsection{Global BIM}

BIM is beginning to change the way we build, the way the buildings look, the way they function and the way buildings are maintained and managed (Godager, 2011). This relatively new technology has allowed a new paradigm within the AEC sector, which has the ability to promote and encourage each stakeholder, within the project, to play a more prominent role. BIM has helped develop the way designers and contractors look at the entire building process, including the initial design brief, all the way through the construction documentation stage, into actual construction management stage, and finally the FM stage (Dzambazova et al, 2009).

The revolution of BIM across the global construction world continues to grow, and must result in Ireland adopting a similar methodology or face been left behind and unable to compete in foreign markets. In order to participate in this lucrative market, Ireland must follow the example of various countries including the USA, Finland, Norway, Denmark, UK, Germany, Singapore and Korea, who are all currently in the process of developing BIM guidelines. Large owners, including the General Services Administration (GSA), the U.S. Army Corps of Engineers (USACE), require BIM deliverables on all major projects (GSA, 2006).

VTT in Finland, Rambøll in Denmark and SINTEF in Norway are the major research organizations in BIM in these countries, as outlined by Wong et al (2009). In Finland, it is required for the use of IFC BIM models on all its projects, with Norway using the Directorate for Public Property and Construction Management for IFC BIM to facilitate the flow of information through whole life cycle. Denmark has a mandated use of 3D/BIM for design and call for tender, and, an electronic handover of information to the client (Government Construction Client Group, 2011).

McGraw Hill (2010) report that in western European countries, such as France, UK and Germany that nearly $60 \%$ of total respondents are currently frequent users and 74\% of Western European BIM users report a positive perceived return on their overall investment in BIM. Outside of the USA and Europe, Singapore is one of the few countries in Asia who have implemented BIM in the public sector, with Hong Kong in the process of establishing BIM guidelines to help increase productivity and meet established high standards that include tight schedules and high land costs. Perhaps most encouraging to the Irish Public Sector, is the move by the UK, towards the legal implementation of BIM by 2016. 
There is a plan for a phased five-year development that projects will be required to use BIM tools and techniques from 2016 within the UK. This strategy was instigated from the recent findings from a report commissioned by the UK Government showing that the UK does not get full value from public sector construction. This key finding resulted in a the need for a new strategy to be drafted that will enable the public sector to become a better client that is more informed and to replace adversarial cultures with collaborative ones. This innovative new procurement system involved the implementation of BIM on all public works projects. In order for this to happen by 2016 it is critical that the industry is brought up to a level 2 standard which is a BIM - File Based Collaboration and Library Management, as illustrated in figure 1.

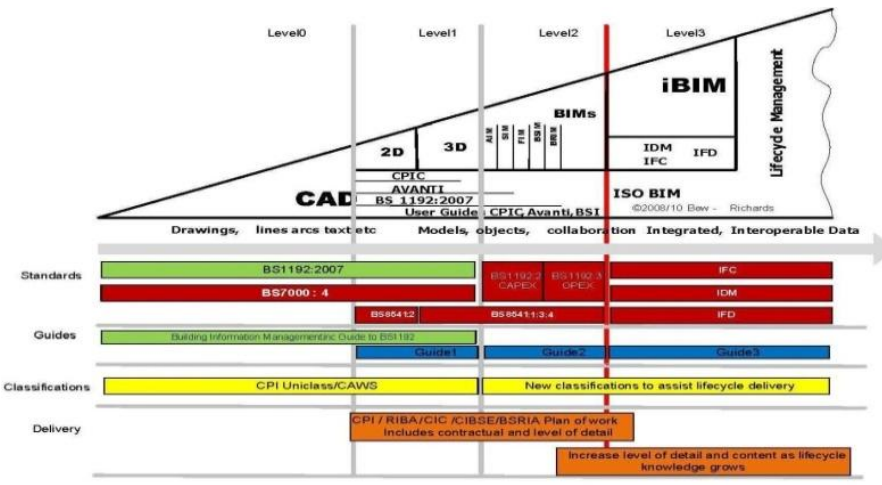

Figure 1.UK roadmap

The overall goal is to achieve a level 3 standard which would be an Integrated Web Service BIM Hub and full open process managed by a collaborative model server. Ireland needs to fall in line with this strategy and begin to adopt a similar hypothesis to our neighbours and move towards the legal imposition of BIM, in order to enhance cost certainty on public works projects and ensure a more carbon neutral future.

\subsection{Barriers to BIM}

In order for Ireland to create a similar frame work to the UK there are a number of obstacle to be addressed in the form of both legal and technical categories. Some of the barriers as stated by McAdam (2010) can range from

- Process - What is the process of implementation i.e. who is required to produce what?

- Interoperability - Will all participants be working from the same software and if not how faithful will there model be to other software been used?

- Use of the Model - The model may be suited to some areas better than other areas, which opens room for error as everyone is working from the same model.
- Status of the model- The extent to which a BIM model could stand as a legal document. The possibility of ambiguity if the contract documents are 2D and the project is constructed in accordance with virtual, collaborative BIM design.

- Cost of BIM - The designer is at the most risk of incurring the cost and not reaping the rewards unless there is a change of practice.

- Design Liability - The extent to which participation may give rise to legal liability, even where no contractual relationship may exist.

- Design Delegation - The delegation of design elements will have to be carefully explored i.e. in certain areas of noncompliance who will be responsible.

- Ownership and protection of Data - In the case of copy right where the legal line will be drawn.

One of the most effective ways to deal with these risks is to have collaborative, integrated project delivery contracts in which the risks of using BIM are shared among the project participants along with the rewards (Azhar,2011). These contracts must include clauses, within the key areas, to address the primary areas of concern, as detailed above. The contracts, as outlined by Wickersham (2009), should distinguish the following key legal areas;

- Digital data protocols. The contract should define the specific software and hardware to be used by project team members for the creation of various elements of the BIM models.

- Coordination and reliance. The contract should define the extent to which team members may rely on each other's contributions to the BIM models, so long as the digital data protocols discussed above are observed.

- Project responsibilities and risks. The contract should ensure that parties do not take on responsibilities that are outside of their scope, fee, and insurable risk, solely by virtue of participating in the creation of the BIM models.

- Copyright / use of documents. The contract should ensure that participation in creation of the BIM models does not inadvertently change the parties' expectations with respect to the copyright and use of the documents they have created specifically negotiated in all project contracts.

- Contractual privity; waivers and indemnities. The contract must state clearly that participation in creation of the BIM 
models does not give rise to contractual privity among participants who have not otherwise entered into agreements.

At present the US has two BIM specific contracts developed, the Consensus DOCs 301 and AIA E202 in which both use standard contracts for which a BIM addendum has been developed. The US Consensus DOCs 301 and AIA E202, through slightly different, offer a starting place in the development of this contract, as they both regulate the following as outlined by Mow and Naylor (2010)

- The project owner's entitlement to use the full design model after completion of the project shall be governed by the contract between the owner and the architect /engineer.

- A limited, non-exclusive license to reproduce, distributes, display, or otherwise use that party's contributions for purposes of this project only.

- Project participants must develop a detailed BIM execution plan. This plan should identify the models to be created, the content of each model, file formats to be used, and measures for interoperability

- The contract addendum limits reliance on any design model to the extent it is included as a contract document.

- The project owner must appoint one or more information managers. The information manager is responsible to protect the model, provide access to the model, and otherwise manage the information within the model.

- If project participants elect not to use E2022008 or Consensus DOCS 301, they must ensure that their custom contracts thoroughly address BIM and its unique influence on the project.

Consensus DOCS 301 puts management of the BIM process at the forefront of its recommendations, and provides much more detail as to issues of ownership and use of the information (McAdam, 2011) .In examining the UK Framework it is concluded that in order to work at a Level 2 that little change is required to the fundamental building blocks of copyright law, contracts or insurance. This is encouraging to an Irish perspective, as our current contracting arrangements are not considerably different to the UK despite the current suite of GCCC forms of contacts not been designed to encourage risk allocation or collaboration.

\section{CITA BIM WORKSHOPS}

\subsection{BIM Pilot Workshop}

The RIAI /CITA BIM Pilot workshop was held over four days with a number of subsequent presentations given to industry leaders. This workshop was used by the authors to test the research topic for this paper by conducting a number of interviews and through the collection of data from the results of the four day pilot. Semi-structured open interviews where used as the main tool of analysis.

\subsubsection{Pilot Overview}

The observer for the BIM project was the DOES and the official observer for the event was the Office of Public Works (OPW). The workshop involved the deconstruction of an existing primary school building model and rebuilding it using BIM technologies, as illustrated in figure 2 . This involved a whole project team working in collaboration to maxamise construction and sustainability potential, through the harnessing of BIM technologies.

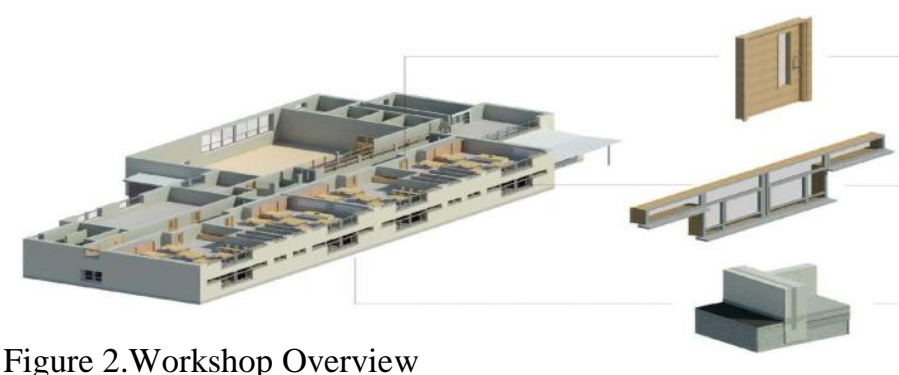

\subsubsection{Pilot Team}

The pilot team consisted of a number of leading design professionals from selected firms within the $\mathrm{AEC} / \mathrm{FM}$ sector, integrated into the design team in order to foster the best method of collaboration. The pilot team was primarily made up of consulting engineers, services engineers, architects, and consultants as illustrated in figure 3 . This team model also consisted of additional support from contractors, quantity surveyors, technical support, facilities management support for handover documentation and BIM energy specialists.

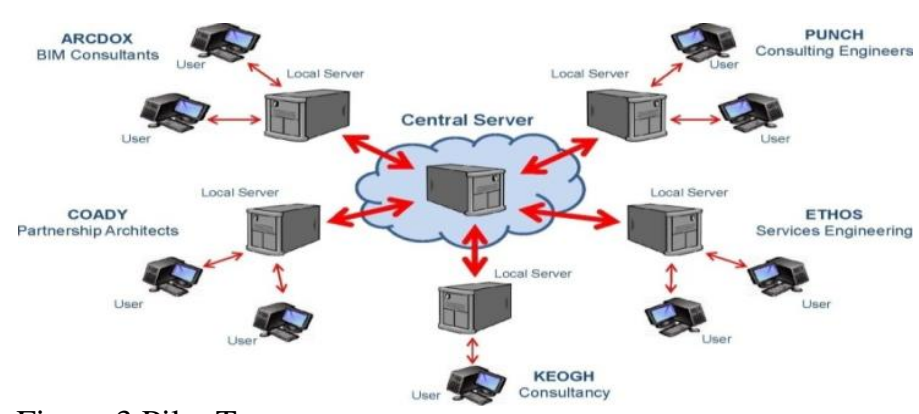

Figure 3.Pilot Team 


\subsubsection{Pilot Activities}

The BIM model was developed to respond to client specific requirements using a visual communication tool to meet their expectations. The design team was provided with a digital brief with the overall goal to design a BIM model of a standard generic DOES school. This model was exploded down to its components and then given to the design team to work on specific components. The various professionals involved all worked on their own model, which was synchronized with a central server, allowing all participants of the workshop to monitor each other's work and, therefore, promoting collaboration.

\subsubsection{Pilot Feedback}

The workshop derived results across all sectors and disciplines and strongly advocated the application of BIM to become mandatory in future public works projects. The BIM model helped identify eventualities that may occur on site and subsequently aided in avoiding these eventualities. Effectively the building was virtually built before having to be built which allowed foresight on a number of key areas. The BIM process added a greater cost certainty and reduced a significant amount of the design risk associated with contractors cost. Through the collaborative process of everyone working on the same model enabled the design team to see what the other disciplines where doing and fostered a greater team ethic throughout the design process. The design team could identify areas of possible clash detection and could instantly confront them before they went to site. This in turn resulted in the cutting down of conflicts and requests for information (RFI's), which are very expensive on site. It was found that the project manager by examining specific tasks on site through a BIM model allowed them to prioritize on site, which resulted in a better, well thought out and managed building.

Energy efficiency according to one of the workshop participants is not a priority at the design stage and decisions on materials section amongst other things are purely driven on cost. The BIM workshop provided the designers with the option to create a number of mass models and to perform exercises in concept energy analysis, so as to, choose the most economical and sustainable building possible. There was also the benefit from extracting digital data directly from the model on each component to develop a digital management tool to aid the Facilities Management process.

\subsection{BIM Workshops}

A suite of BIM workshops where commissioned in 2012 in which were to be primarily hosted by the Construction IT Alliance (CITA). These workshops were to be sponsored by professional institutions with the overreaching aim of promoting BIM within the Irish AEC/FM industry.

\subsubsection{Overview}

The first workshop was based around setting an aligned policy for use of BIM in regards to a top down strategy for Government, Institutions, companies and projects. There was over 150 leading professionals involved within this workshop in which a number of questions where addressed in a round table discussion. Each table discussed the outlined questions in great detail below:

1. Should the Irish Government follow the UK Government's decision in mandating the use of BIM on public sector projects?

2. How best can the Irish Construction industry, lobby / influence the decision of the Irish Government in regard to BIM?

This workshop served as an additional primary research tool for this paper and provided further data in regards to testing the implementation of BIM on public works projects. The authors where responsible for the collection and analysis of data from this workshop.

\subsubsection{Roundtable Discussion}

There was a resounding agreement that the Irish Government should follow the UK Government's decision in mandating the use of BIM on public sector projects. The delegates felt this would result in cost and waste reduction, allow re-investment into the industry, create job opportunities and promote a more efficient industry. The legal mandating of BIM can be the driver to make the industry more technically aware and will provide the tools for the Irish Construction sector to compete in International markets.

The mandating of BIM can also help in ensuring a more up skilled workforce and graduates, as well as, the overall improvement of lifecycle costs, due to better management of data. There was a strong call for the Government to provide incentives through the provision of grants before moving towards the mandating of BIM. There were concerns noted in regards to the impact that the legal mandating of BIM may have on SME's, with the Government possibly reluctant to be seen discriminating against these companies. Another barrier facing BIM is the further possible reluctance of the Government to incorporate more change, due to the, recent introduction of the GCCC forms of contract. At present BIM does not fit into the Government procurement route, which is not set up to promote the collaboration required for a successful BIM model to be produced.

In order for the Irish Construction industry to best lobby/influence the decision of the Irish Govern- 
ment, it is suggested that there must be single voice in the form of a Chief Construction Advisor such as in the UK. There is the need for a professional body that will be responsible for making the Government take notice of the need for change in the industry, so as to, ensure competiveness and the ability to compete in foreign markets. The Government as a procurer must also be educated to the overall potential that BIM can offer, and therefore, potentially resulting in possible incentives been introduced into the industry to help promote the eventual mandating of BIM.

\subsection{Triangulation of results}

The pilot workshop has offered the opportunity for a whole design team to break a constructed primary school down to its core elements, and re-build it using a BIM platform, which would focus on best construction practice in regards to its overall life cycle. In general it was found that BIM can add more cost certainty and can take away a lot of design risk, as the mass model studies allow design teams to design to a cost, rather than cost to design. The BIM Model allowed a data rich model, allowing testing of design solutions to provide a more responsive building design to the client brief, and, better coordination of all project information. The workshop proved a success and provided the platform for the Irish Government to see first-hand, how a collaborative BIM model used on a public works projects could provide the cost certainty they so urgently seek.

The pilot workshop established the benefits of a BIM approach to Government Departments but did not address the strategy to implement BIM on public works projects. Building on the success of the pilot, the first of a suite of BIM workshops set about investigating creating an aligned strategy for BIM in Ireland similar to that of the UK. The UKs 5 year plan to implement BIM actioned a number of key areas that included investment, legal requirement, improved project handover, programme delivery and institutional support. The BIM workshop addressed these areas in which the Irish AEC / FM sector was found trailing in all areas. There is currently little incentive from the Government and the current GCCC forms of contracts are not set up in a manner to incorporate BIM. At present there are no plans for the research and development of a BIM programme and no solution been put forward to improving project handover data. There is though encouraging support from professional institutions, as seen from the commissioning of the pilot and subsequent suite of workshops. There is also at present a BIM based postgraduate course in Building Information Management to be offered by CITA and Dublin Institute of Technology in September 2012, which will go some way to the up skilling of future graduates.

\section{CONCLUSION}

The lack of compatible systems, standards and protocols, and the differing requirements of clients and lead designers, has inhibited widespread adoption of a technology on public sector project. These technologies have the capacity to ensure that all team members are working from the same data, and that the implications of alternative design proposals can be evaluated with comparative ease. The UK government's move to demand by 2016 that projects are modeled in three dimensions will lead to eliminating coordination errors and subsequent expensive changes, which was at the foundation of historical public sector project delivery in the past. The seamless integration of design data which can be fed directly to machine tools can create a link between design and manufacture, helping to eliminate unnecessary intermediaries; and ensuring a proper basis for asset management subsequent to construction.

On revisiting the authors original objectives it was found through the analysis of the pilot and workshop, that BIM can address the following specific goals of the CWMF;

1. Greater cost certainty- BIM can provide a greater cost certainty at contract award stage, as the mass model studies allow design teams to design to a cost, rather than cost to design;

2. Award contracts on the basis of a lump-sum fixed-price - The BIM model provides exercises in design, programming, cost and value management and concept energy analysis. This allows a more accurate financial assessment for a contract with a fixed price.

3. Rebalance the risk - The risk factor can be better predicted through having a virtual model which enables clash detection and avoidance of a number of eventualities.

4. Value for Money - BIM enables a whole life cycle approach, through its unique access to a combination of energy analysis tools that complement the BIM process. This approach offers a much greater value for money to the client as it addresses their needs over the structures life.

5. Efficient delivery of the projects - BIM enables testing of design solutions to provide a more responsive building design to the client brief, and, better coordination of all project information.

Despite the success of the pilot and workshop, Ireland is still a long way from embracing BIM on public works projects. Representatives of the OPW 
noted that despite the benefits that BIM would have on a number of Departments within the Government, it would still require "an act of faith" for the Irish Government to fully embrace it. The legal mandating of BIM may further be viewed as discriminating on SME's and there may be reluctance to incorporate more changes, due to the, recent introduction of the GCCC forms of contract. This fact, coupled with the fear of legal implications, such as, who owns the BIM model and which profession will carry most liability for the model, have left the Irish AEC / FM sector in an uncertain stance towards the mandating of BIM on public works.

The future workshops will address a number of key areas, such as contractual implications, development of a BIM Library, process change management, the up skilling of existing workforce and technical standards. These further workshops will serve as the focus for the central role that BIM can play in ensuring the practice of design, construction and facilities management for a long-term sustainable solution for the build environment.

\section{Acknowledgements}

The authors would like to acknowledge the following firms who contributed both towards the RIAI / CITA Workshop and this paper:

- DOES / OPW

- RIAI / CITA

- ArcDox / Coady Partnership

- Punch Consulting Engineers

- Ethos Engineering

- Kerrigan Sheanon Newman

- Keogh Consultancy / Stewart Construction

- Moore DFM / Datech / Diatec

\section{REFERENCES}

Azhar, S. (2011) Building Information Modeling (BIM): Trends, Benefits, Risks, and Challenges for the AEC Industry, Leadership and Management in Engineering, July 2011, pp241 - 252

CITA / RIAI (2011) CITA RIAI BIM Workshop, RIAI 8 Merrion Square Dublin 2, 1st - 4th November.

CITA BIM Workshop (2012) Setting aligned policy for the use of BIM: A top down strategy, CITA available at $<$ http://www.cita.ie/workshpsum1.asp> accessed $(09 / 03 / 2012)$

Dzambazova, T., Krygiel, E. \& Demchak, G. (2009) Introducing Revit ${ }^{\circledR}$ Architecture 2010: BIM for Beginners, Understanding BIM, Chapter 1, pg1, Sybex

Edge, Derrick, (2006) Annual Dinner-President Speech, Association of Consulting Engineers of Ireland, Available at<www.acei.ie/2006_presidents_speech.asp (accessed 08/11/11)

Fogarty, Dan. (2007) CIF: New contracts to push up price of construction, Breaking News, Available at < http://www.breakingnews.ie/world/cif-new-contracts-to- push-up-price-of-construction-309963.html>accessed $(8 / 11 / 11)$

Fogarty, Dan. (2011) Contractor perspective of the new Irish Public Works Projects, Management Procurement and Law, Proceedings of the Institution of Civil Engineers, February 2009, pp 29-34

GSA. (2006). GSA BIM Guide for Spatial Program Validation. Version 0.90

Godager, B. (2011) Analysis of the Information Needs for Existing Buildings for Integration in Modern BIM-Based Building Information Management, Proceedings of the 8th International Conference May 19-20, 2011, Vilnius, Lithuania

Government Construction Client Group (2011) A report for the Government Construction Client Group Building Information Modeling (BIM) Working Party Strategy Paper March 2011, UK Government

Henstridge (2011) Construction in the UK and Ireland on the mend, but recovery is slow and unsteady, The European Business Review, available at < http://www.europeanbusinessreview.com/?p=3595> accessed (15/03/12)

Irish Times (2010) Green firms to get priority in contracts says Gormley, Irish Times, available at

<http://www.irishtimes.com/newspaper/ireland/2010/0522/1 224270894108.html >accessed [06/03/2012].

Irish Times (2010) Quinn unveils schools programme, Irish Times, available at $<$

http://www.irishtimes.com/newspaper/breaking/2012/0312/ breaking13.html?via=mr $>$ accessed [06/03/2012].

Jick, T (1979) Mixing Qualitative and Quantitative Methods: Triangulation in Action, Administrative Science Quarterly, December, Vol 24.

Mason Hayes and Curren (2012) Investing in Ireland, Construction, available at < http://www.mhc.ie/investing-inireland/construction $>$ accesss $(16 / 03 / 2012)$

McAdam, B. (2010) Building information modeling: the UK legal context, International Journal of Law in the Built Environment, Vol. 2 No. 3, pp. 246-259

McGraw \& Hill (20) McGraw - Hill Construction (2010b) The Business Value of BIM in Europe - Getting BIM to the bottom line in the UK, France and Germany, Smart Market Report

Mow, A.T and Naylor, K. J (2010) Navigating the legal landscape of BIM, Design Intelligence, available at < http://www.di.net/articles/archive/navigating_legal_landsca pe bim/> accessed (09/03/12)

Tobin, M (2004) Statement by Mr Michael Tobin, Chief Executive NRA, to the Committee of Public Accounts on 15th July, 2004, available at < http://www.nra.ie/News/PressReleases/2004/htmltext,2467,e n.html > accessed (27/03/2012)

Wren, T. (2011) The Irish Works Contract Major Forms Contract 3: Damage. Loss and Inquiry Analysis, available at www.tomwren.ie/GCCC 3.pdf > accessed (14/03/2012)

Wickersham, J. (2009) Legal and Business Implications of Building Information Modeling (BIM) and Integrated Project Delivery (IPD), Rocket: BIM-IPD legal and business issues,

Wong, A.K.D, Wong, F.K.W. \& Nadeem, A. (2010) Government roles in implementing building information modeling systems Comparison between Hong Kong and the United States, Construction Innovation, Vol. 11 No. 1, pp. 61-76

Wong, A.K.D, Wong, F.K.W. \& Nadeem, A. (2009) Comparative Roles of Major Stakeholders for the Implementation of BIM in Various Countries, Integration And Collaboration 3, Changing Roles 